\title{
Screening and characterization of rhizobacterial strains of Bacillus spp. isolated from rhizosphere of cauliflower (Brassica oleracea var. botrytis L.)
}

\author{
Manoj Kaushal* and Rajesh Kaushal \\ Department of Basic Science, Dr Y. S. Parmar University of Horticulture and Forestry, Nauni, Solan, Himachal Pradesh \\ 173230 India. \\ Accepted 29 September, 2011
}

\begin{abstract}
A total of $\mathbf{4 0}$ isolates were isolated from different rhizospheric soil and roots of cauliflower from the vicinity of three districts (Kangra, Hamirpur and Bilaspur) of Himachal Pradesh belonging to sub temperate Himalayan location. Thereafter, these isolates were screened and characterized for their plant growth promotion and biocontrol properties as per standard methods. Out of 40, only 5 isolates $\left(\mathrm{MK}_{2}, \mathrm{MK}_{4}, \mathrm{MK}_{5}, \mathrm{MK}_{7}\right.$ and $\mathrm{MK}_{9}$ ) showed maximum plant growth promoting attributes like $\mathrm{P}$ - solubilization, $\mathrm{N}$ - fixation etc. All the five isolates solubilized tricalcium phosphate under in vitro conditions however, $\mathrm{MK}_{5}$ and $\mathrm{MK}_{7}$ had highest phosphate solubilizing efficiency of 172.21 and $166.67 \%$ were recorded. Production of IAA, HCN and siderophore demonstrated in broth assay were other important plant growth promoting characters. The isolates produced diffusible and volatile compounds that inhibited the growth of three soil borne phytopathogens namely Fusarium sp., Rhizoctonia solani and Pythium sp. The carrier based formulations of these isolates resulted in increased plant growth in bioassays. The isolate $\mathrm{MK}_{5}$ showed maximum homology (99\%) with Bacillus subtilis (HQ594544) and isolate $\mathrm{MK}_{7}$ showed homology (100\%) with Bacillus pumilus (GU290547) by 16S rRNA analysis.
\end{abstract}

Key words: Bacillus sp., cauliflower, Plant growth promoting rhizobacteria (PGPR), P-solubilization, biocontrol.

\section{INTRODUCTION}

Plant growth promoting rhizobacteria (PGPR) were first defined by Kloepper and Schroth (1978) as beneficial rhizobacteria that colonize the roots and exert beneficial effects on plant growth and development. The growth enhancement may be direct by the production of phytohormones and/or by increasing the available nutrients through production of secondary metabolites to solubilize native $\mathrm{P}$ content, siderophore producers or indirect means as biocontrol agent that are able to protect plant from infections by phytopathogenic organisms through production of antibiotics, $\mathrm{HCN}$ and cell wall degrading enzymes. PGPR have been applied to various crops to enhance seed emergence, growth and crop yield (Cleyet-Marcel et al., 2001), but only a few isolate

\footnotetext{
*Correspondence author. E-mail: adishrk@rediffmail.com.
}

have been commercialized (Dey et al., 2004). The most predominant rhizosphere colonizing bacteria belong to genus Pseudomonas and Bacillus because of their association with soil organic matter, nutritional diversity and rapid growth rate. The extent of benefits from PGPR depends on their number and efficiency which is governed by a large number of soil and environmental factors. PGPR are likely to be of great interest in sustainable crop production and growth promotion. Significant enhancement in plant growth or control of pathogens by PGPR has been demonstrated under laboratory and net house conditions. In the present study, two efficient rhizobacterial strains of Bacillus subtilis $\left(\mathrm{MK}_{5}\right)$ and Bacillus pumilus $\left(\mathrm{MK}_{7}\right)$ isolated from soil and root samples collected from rhizosphere of cauliflower of sub temperate locations in Himachal Pradesh has been characterized with special reference to their plant growth promoting abilities. 


\section{MATERIALS AND METHODS}

Soil samples (up to $15 \mathrm{~cm}$ depth) were collected from rhizosphere (with roots) of cauliflower from three (Kangra, Hamirpur and Bilaspur) naturally growing agro-climatic zones of Himachal Pradesh. The samples were placed in plastic bags and stored in Soil Microbiology Laboratory of Department of Soil Science and Water Management for further isolation and analysis work. The isolation of the microorganisms was carried out from eight sites at different locations in Bilaspur (Namhol and Jukhala), Hamirpur (Bhota and Nadaun) and Kangra (Palampur, Dharamshala, Jachh and Pong Dam) area of Himachal Pradesh.

\section{Isolation from soil and root samples}

Isolation from soil and root samples was done by modified replica plating technique. After incubation of 24 to $48 \mathrm{~h}$, the isolated colonies that developed on enriched medium (master plate) were replica plated onto the selective media: Nitrogen free medium (Jensen, 1987) for nitrogen fixing activity, Pikovskaya medium (Pikovskaya, 1948) for phosphate solubilizing ability.

\section{Maintenance of the cultures}

The isolated cultures were purified by streak plate method and maintained on the slants of respective medium at $4^{\circ} \mathrm{C}$ in refrigerator. The culture of Rhizoctonia solani, Pythium sp. and Fusarium sp. were procured from Department of Mycology and Plant Pathology, University of Horticulture and Forestry, Nauni, Solan. Fungal cultures were maintained on malt extract agar at $4^{\circ} \mathrm{C}$.

\section{Screening and characterization of bacterial isolates}

The screening of the bacterial isolates for various plant growth promoting activities were performed by adopting the standard methods. Estimation of P- solubilization in liquid PVK medium containing tri-calcium phosphate (TCP) was determined as described by Bray and Kurtz (1945). Phosphate solubilizing activity, nitrogen fixing ability, siderophore production, HCN production, IAA production and antagonistic activity was determined by Pikovskaya (1948), Jensen (1987), Schwyn and Neilands (1987), Bakker and Schippers (1987), Gordon and Paleg (1957) and Vincent (1970) respectively.

\section{Molecular characterization of selected isolate}

Primers specific for best isolate will be developed based on the $16 \mathrm{~S}$ rRNA gene sequence and were evaluated by polymerase chain reaction (PCR) performed with genomic DNA from selected isolates.

\section{RESULTS AND DISCUSSION}

\section{Isolation and enumeration of rhizospheric and endophytic rhizobacteria}

\section{Microbial population in rhizosphere soil}

The rhizosphere soil had great variation in total microbial counts at different locations. Among various sites, Bhota had highest $\left(291.0 \times 10^{4} \mathrm{cfu} / \mathrm{g}\right.$ soil $)$ and Nadaun had the minimum $\left(180.3 \times 10^{4} \mathrm{cfu} / \mathrm{g}\right.$ soil $)$ bacterial counts. The population on the Jensen's medium which is specific for $\mathrm{N}$-fixation was highest $\left(72.3 \times 10^{4} \mathrm{cfu} / \mathrm{g}\right.$ soil $)$ at Jachh and lowest $\left(56.0 \times 10^{4} \mathrm{cfu} / \mathrm{g}\right.$ soil) was found for Jukhala. The percentage of phosphate solubilizing microorganisms to total PVK count ranged from $61.30 \%$ (Jukhala, Bilaspur) to $75.60 \%$ (Nadaun, Hamirpur).

\section{Microbial population in the roots of cauliflower plants}

Cauliflower roots collected from different location/sites harboured variable microbial population. The highest $\left(101.7 \times 10^{1} \mathrm{cfu} / \mathrm{g}\right.$ root$)$ total bacterial count was found at Nadaun however, the lowest $\left(62.3 \times 10^{1} \mathrm{cfu} / \mathrm{g}\right.$ root $)$ was noted at Jukhala. The maximum $\left(47.7 \times 10^{1} \mathrm{cfu} / \mathrm{g}\right.$ root $)$ endophytic bacterial population capable of $\mathrm{N}$-fixation was recorded for Nadaun and the minimum $\left(33.3 \times 10^{1} \mathrm{cfu} / \mathrm{g}\right.$ root) was noted for Namhol. Percent phosphate solubilizers to the total population on PVK medium at different location/sites varied from $45.3 \%$ at Namhol (Bilaspur) to $61.3 \%$ at Nadaun (Hamirpur).

\section{Screening and characterization of bacterial isolates}

Qualitative and quantitative estimation of TCP solubilization by bacterial isolates

Phosphorus is one of the major nutrients, second only to nitrogen in requirement for plants. Most of phosphorus in soil is present in the form of insoluble phosphates and cannot be utilized by the plants. PGPR have been shown to solubilize precipitated phosphates and enhance phosphate availability to cauliflower that represents a possible mechanism of plant growth promotion under field conditions (Verma et al., 2001). In our experiments, all isolates were able to solubilize phosphate in the rhizosphere soil. It is important to note that several phosphate-solubilizing bacilli occur in soil (Skrary and Cameron, 1998) but their numbers are not usually high enough to compete with other bacteria commonly established in the rhizosphere (Lifshitz et al., 1987). All the five isolates $\left(\mathrm{MK}_{2}, \mathrm{MK}_{4}, \mathrm{MK}_{5}, \mathrm{MK}_{7}\right.$ and $\left.\mathrm{MK}_{9}\right)$ were found to solubilize TCP in PVK agar medium (Table 1).

\section{Indole-3-acetic acid production by bacterial isolates}

The data presented in Table 2 revealed that isolate $\mathrm{MK}_{5}$ produced a significantly higher concentration of IAA $(29.67 \mu \mathrm{g} / \mathrm{ml})$ corresponding maximum $\left(60.67 \times 10^{5}\right.$ $\mathrm{cfu} / \mathrm{ml}$ ) viable count as compared to other tested isolates. It has been reported that IAA production by PGPR can vary among different species and strains, and it is also influenced by culture condition, growth stage and substrate availability (Mirza et al., 2001). 
Table 1. Solubilization of Tri calcium Phosphate (TCP) by selected bacterial isolates in solid and liquid Pikovskaya's medium.

\begin{tabular}{|c|c|c|c|}
\hline \multirow{2}{*}{$\begin{array}{l}\text { Bacterial } \\
\text { isolates }\end{array}$} & \multicolumn{2}{|c|}{ P-solubilization in solid medium } & \multirow{2}{*}{$\begin{array}{l}\text { P-solubilization in liquid medium } \\
\qquad(\mu \mathrm{g} / \mathrm{ml})\end{array}$} \\
\hline & $\begin{array}{l}\text { Phosphate solubilization index } \\
\text { (PSI) }\end{array}$ & $\begin{array}{c}\text { \% P-solubilization efficiency } \\
\text { (\%SE) }\end{array}$ & \\
\hline $\mathrm{MK}_{2}$ & 2.67 & $151.36(12.27)^{\star}$ & $444.33(2.64)^{\star \star}$ \\
\hline $\mathrm{MK}_{4}$ & 2. 47 & $147.22(11.90)$ & $567.67(2.73)$ \\
\hline $\mathrm{MK}_{5}$ & 2.76 & $172.21(13.06)$ & $664.33(2.82)$ \\
\hline $\mathrm{MK}_{7}$ & 2.77 & $166.67(12.87)$ & $640.33(2.80)$ \\
\hline $\mathrm{MK}_{9}$ & 2.75 & $158.33(12.54)$ & $604.00(2.77)$ \\
\hline Isd & 0.28 & $(0.78)$ & $(0.06)$ \\
\hline
\end{tabular}

${ }^{*}$ Figures in parentheses are square root transformed values, ${ }^{* *}$ Figures in parentheses are log transformed values.

Table 2. Indole-3-acetic acid production by selected bacterial isolates in Luria Bertani Broth.

\begin{tabular}{lccc}
\hline Bacterial isolates & Viable count $\left(\mathbf{1 0}^{\mathbf{5}} \mathbf{c f u} / \mathbf{m l}\right)$ & Final $\mathbf{p H}$ of supernatant & Indole-3-acetic acid $(\boldsymbol{\mu g} / \mathbf{m l})$ \\
\hline $\mathrm{MK}_{2}$ & 47.67 & 5.10 & 24.83 \\
$\mathrm{MK}_{4}$ & 58.33 & 5.20 & 24.67 \\
$\mathrm{MK}_{5}$ & 60.67 & 5.13 & 29.67 \\
$\mathrm{MK}_{7}$ & 56.67 & 5.18 & 28.33 \\
$\mathrm{MK}_{9}$ & 58.67 & 5.22 & 25.50 \\
Isd & 3.19 & 0.09 & 3.26 \\
\hline
\end{tabular}

Table 3. Qualitative and quantitative estimation of siderophore activity by selected bacterial isolates on CAS medium.

\begin{tabular}{lcccc}
\hline \multirow{2}{*}{$\begin{array}{l}\text { Bacterial } \\
\text { isolates }\end{array}$} & $\begin{array}{c}\text { Viable count } \\
(\times \mathbf{1 0} \mathbf{c f u} / \mathbf{m l})\end{array}$ & $\begin{array}{c}\text { Final } \mathbf{~ p H} \text { of } \\
\text { supernatant }\end{array}$ & $\begin{array}{c}\text { Siderophore activity } \\
\text { Qualitative estimation } \\
(\text { Zone size, } \mathbf{m m})\end{array}$ & $\begin{array}{c}\text { Quantitative estimation } \\
(\% \text { siderophore unit })\end{array}$ \\
\hline $\mathrm{MK}_{2}$ & 51.63 & 5.10 & 8.67 & $19.86(26.37)$ \\
$\mathrm{MK}_{4}$ & 52.67 & 5.22 & 11.33 & $19.40(26.01)$ \\
$\mathrm{MK}_{5}$ & 48.33 & 5.12 & 12.67 & $51.36(45.78)$ \\
$\mathrm{MK}_{7}$ & 48.67 & 5.23 & 13.33 & $33.03(35.03)$ \\
$\mathrm{MK}_{9}$ & 49.67 & 5.14 & 14.67 & $31.14(33.90)$ \\
Isd & 3.29 & 0.12 & 2.77 & 15.94 \\
\hline
\end{tabular}

\section{Siderophore production by selected bacterial isolates}

In our study, all the five bacterial isolates produced a bright zone with yellowish colour around the bacterial colony on Chrome-azurol-S (CAS) medium. Maximum $(14.67 \mathrm{~mm})$ bright zone with yellowish colour was observed in case of $\mathrm{MK}_{9}$. Quantitative estimation of siderophore using Chrome-azurol-S (CAS) liquid assay (Table 3) revealed that bacterial isolate $\mathrm{MK}_{5}$ produced maximum (51.36\% siderophore unit) at $72 \mathrm{~h}$ of incubation and maximum $\left(52.67 \times 10^{5} \mathrm{cfu} / \mathrm{ml}\right)$ viable count after $72 \mathrm{~h}$ of incubation corresponded to isolate $\mathrm{MK}_{4}$.

\section{HCN production by bacterial isolates}

All the bacterial isolates were screened for $\mathrm{HCN}$ production on King's $\mathrm{B}$ medium. Only the isolates $\mathrm{MK}_{5}$ and $\mathrm{MK}_{7}$ caused change of colour of filter paper from yellow to orange and to dark brown. 
Table 4. Antifungal activity of selected bacterial isolates against fungal pathogens using dual culture technique.

\begin{tabular}{lccc}
\hline \multirow{2}{*}{ Bacterial isolates } & \multicolumn{3}{c}{ Antifungal activity (\% growth inhibition) } \\
\cline { 2 - 4 } & $81.81(9.04)$ & Pythium sp. & Fusarium sp. \\
\hline $\mathrm{MK}_{2}$ & $78.40(8.85)$ & $83.72(9.14)$ & $83.33(9.12)$ \\
$\mathrm{MK}_{4}$ & $84.09(9.16)$ & $81.39(9.02)$ & $90.38(9.50)$ \\
$\mathrm{MK}_{5}$ & $77.27(8.78)$ & $86.04(9.26)$ & $89.28(9.44)$ \\
$\mathrm{MK}_{7}$ & $81.81(9.04)$ & $81.39(9.02)$ & $85.71(9.25)$ \\
$\mathrm{MK}_{9}$ & $(0.21)$ & $77.90(8.82)$ & $88.09(9.38)$ \\
Isd & & $(0.26)$ & $(0.23)$ \\
\hline
\end{tabular}

Figures in parentheses are square root transformed values.

\section{Characterization of the bacterial isolates for antifungal activity}

The antifungal activity of individual isolates was compared using dual culture method (Table 4). $\mathrm{MK}_{4}$ bacterial isolate, in general, showed maximum growth inhibition against Fusarium sp. (90.38\%). Bacterial isolate $\mathrm{MK}_{5}$ showed comparatively maximum growth of inhibition $(84.09 \%)$ against Rhizoctonia solani. The $\mathrm{MK}_{5}$ isolate showed maximum growth of inhibition (86.04\%) against Pythium sp. A large body of evidence suggests that PGPR enhance the growth and crop yield, and contribute to the protection of plants against certain pathogens and pests (Minorsky, 2008).

\section{Molecular characterization (16S rRNA gene sequencing) of efficient native PGPR isolates}

An attempt was made to characterize the efficient bacteria isolated from the rhizosphere of cauliflower plants using 16S rRNA gene sequencing to identify and decipher their phylogenetic affilation of these bacteria. Sequence data of 16S rRNA gene of two efficient strains obtained through automated sequencer using eubacterial universal primers revealed 1409 bp partial sequence in isolates $\mathrm{MK}_{5}$ and $\mathrm{MK}_{7}$ (Figure 1).

The 16S rRNA gene sequence is about 1,500 bp long and is composed of both variable and conserved regions. Universal primers are usually chosen as complementary to the conserved regions at the beginning of the gene or at either the $540 \mathrm{bp}$ region or at the end of the whole sequence (about the 1,500 bp region), and in between sequence of the variable region is used for the comparative taxonomy (Relman, 1999). The gene is large enough, with sufficient interspecific polymorphisms, to provide distinguishing and statistically valid measurements. The 16S rRNA gene serve as molecular chronometer, since it is the most conserved part during evolution (Clarridge 2004). Therefore, 16S rRNA gene sequencing is used and accepted worldwide for identification and phylogenetic analysis of the bacterium.

\section{Nucleotide sequence analysis}

Nucleotide sequence analysis of test isolates using clustalW program revealed that isolate $\mathrm{MK}_{5}$ showed maximum homology (99\%) with B. subtilis (HQ594544) and isolate $\mathrm{MK}_{7}$ showed homology (100\%) with $B$. pumilus (GU290547). The test bacterial isolates clustered with members of the genera Bacillus, thus differentiating the bacterial isolates on the genetic basis. Earlier workers have also reported the isolation of these genera from the rhizosphere of various crop plants (Chan et al., 1994).

The pair wise genetic distance of the two efficient isolates with other selected sequences from the national centre for biotechnology information (NCBI) is depicted in Table 5. The pair wise genetic distance of the isolates viz., $\mathrm{MK}_{5}$ and $\mathrm{MK}_{7}$ with other selected sequences ranged from 0.004 to 0.302 . Dendrogram based on phylogenetic analysis presented in Plate 1 shows that the two isolates viz., $\mathrm{MK}_{5}$ and $\mathrm{MK}_{7}$ clustered with Bacillus a typical Firmicute.

Various other workers also used this technique for identification and phylogenetic analysis of the isolates (Catara et al., 2002). Therefore, to get reliable and accurate identification of bacterial isolates, molecular characterization (16S rRNA gene sequencing) is an important tool. Taken together, results suggest that PGPR are able to induce the production of IAA, solubilization of phosphorus, and resistance to pathogens and pests, thereby improving growth of plants. The use of PGPR as inoculants biofertilizers is an efficient approach to replace chemical fertilizers and pesticides for sustainable cauliflower cultivation in Himachal Pradesh. 
1 AgTCGAGCGGACAGATGGGAGCTTGCTCCCTGAATAGTTAAgCAGGCGGACGgGTGAGTAACACGTGGGT 70 71 AACCTGCCTGTAAGACTGGGATAACTCCGGGAAACCGGGGCTAATACCGGATGGTTGTTTGAACCGCATG 140 141 GTTCAAACATAAAAGGTGGCTTCGGCTACCACTTACAGATGGACCCGCGGCGCATAGCTAGTTGGTGAGG 211 TAACGGCTCACCAAGGCAACGATGCGTAGCCGACCTGAGAGGGTGATCGGCCACACTGGGACTGAGACAC 281 GGCCCAGACTCCTACGGGAGGCAGCAGTAGGGAATCTTCCGCAATGGACGAAAGTCTGACGGAGCAACGC 351 CGCGTGAGTGATGAAGGTTTTCGGATCGTAAAGCTCTGTTGTTAGGGAAGAACAAGTACCGTTCGAATAG 421 GGCGGTACCTTGACGGTACCTAACCAGAAAGCCACGGCTAACTACGTGCCAGCAGCCGCGGTAATACGTA 491 GGTGGCAAGCGTTGTCCGGAATTATTGGGCGTAAAGGGCTCGCAGGCGGTTTCTTAAGTCTGATGTGAAA 561 GCCCCCGGCTCAACCGGGGAGGGTCATTGGAAACTGGGGAACTTGAGTGCAGAAGAGGAGAGTGGAATTC 631 CACGTGTAGCGGTGAAATGCGTAGAGATGTGGAGGAACACCAGTGGCGAAGGCGACTCTCTGGTCTGTAA 701 CTGACGCTGAGGAGCGAAAGCGTGGGGAGCGAACAGGATTAGATACCCTGGTAGTCCACGCCGTAAACGA 771 TGAGTGCTAAGTGTTAGGGGGTTTCCGCCCCTTAGTGCTGCAGCTAACGCATTAAGCACTCCGCCTGGGG 841 AGTACGGTCGCAAGACTGAAACTCAAAGGAATTGACGGGGGCCCGCACCAGCGGTGGAGCATGTGGTTTA 911 ATTCGAAGCAACGCGAAGAACCTTACCAGGTCTTGACATCCTCTGAAATCCTAGAGATAGGACGTCCCCT 981 TCGGGGGCAGAGTGACAGGTGGTGCATGGTTGTCGTCAGCTCGTGTCGTGAGATGTTGGGTTAAGTCCCG 1051 CAACGAGCGCAACCCTTGATCTTAGTTGCCAGCATTCAGTTGGGCACTCTAAGGTGACTGCCGGTGACAA 1120 1121 ACCGGAGGAAGGTGGGGATGACGTCAAATCATCATGCCCCTTATGACCTGGGCTACACACGTGCTACAAT 1190 1191 GGACAGAACAAAGGGCAGCGAAACCGCGAGGTTAAGCCAATCCCACAAATCTGTTCTCAGTTCGGATCGC 1260 1261 AGTCTGCAACTCGACTGCGTGAAGCTGGAATCGCTAGTAATCGCGGATCAGCATGCCGCGGTGAATACGT 1330 1331TCCCGGGCCTTGTACACACCGCCCGTCACACCACGAGAGTTTGTAACATCCGAAGTCGGTGAGGTAACCT 1400 1401 CTTAGGAGC

1 AGTCGGAGCGGACAGAAGGGAGCTTGCTCCCGGATAGTTAACAGGCGGACGGGTGAGTAACACGTGGGTA 70 71 ACCTGCCTGTAAGACTGGGATAACTCCGGGAAACCGGAGCTAATACCGGATAGTTCCTTGAACCGCAGGT 140 141 TCAAGGATGAAAGACGGTTTCGGCTGTCACTTACAGATGGACCCGCGGCGCATAGCTAGTTGGTGGGGTA 210 211 ATGGCTCACCAAGGCGACGATGCGTAGCCGACCTGAGAGGGTGATCGGCCACACTGGGACTGAGACACGG 280 281 CCCAGACTCCTACGGGAGGCAGCAGTAGGGAATCTTCCGCAATGGACGAAAGTCTGACGGAGCAACGCCG 350 351 CGTGAGTGATGAAGGTTTTCGGATCGTAAAGCTCTGTTGTTAGGGAAGAACAAGTGCGAGAGTAACTGCT 420 421 CGCACCTTGACGGTACCTAACCAGAAAGCCACGGCTAACTACGTGCCAGCAGCCGCGGTAATACGTAGGT 490 491 GGCAAGCGTTGTCCGGAATTATTGGGCGTAAAGGGCTCGCAGGCGGTTTCTTAAGTCTGATGTGAAAGCC 560 561 CCCGGCTCAACCGGGGAGGGTCATTGGAAACTGGGAAACTTGAGTGCAGAAGAGGAGAGTGGAATTCCAC 630 631 GTGTAGCGGTGAATTGCGTAGAGATGTGGAGGAACACCAGTGGCGAAGGCGACTCTCTGGTCTGTAACTG 700 701 ACGCTGAGGAGCGATAGCGTGGGGAGCGAACAGGATTAGATACCCTGGTAGTCCACGCCGTAAACGATGA 770 771 GTGCTAAGTGTTAGGGGGTTTCCGCCCCTTAGTGCTGCAGCTAACGCATTAAGCACTCCGCCTGGGGAGT 840 841 ACGGTCGCAAGACTGAAACTCAAAGGAATTGACGGGGGCCCGCACCAGCGGTGGAGCATGTGGTTTAATT 910 911 CGAAGCAACGCGAAGAACCTTACCAGGTCTTGACATCCTCTGACAACCCTAGAGATAGGGCTTTCCCTTC 980 981 GGGGACAGAGTGACAGGTGGTGCATGGTTGTCGTCAGCTCGTGTCGTGAGATGTTGGGTTAAGTCCCGCA 1050 1051 ACGAGCGCAACCCTTGATCTTAGTTGCCAGCATTCAGTTGGGCACTCTAAGGTGACTGCCGGTGACAAAC 1120 1121 CGGAGGAAGGTGGGGATGACGTCAAATCATCATGCCCCTTATGACCTGGGCTACACACGTGCTACAATGG 1190 1191 ACAGAACAAAGGGCTGCAAGACCGCAAGGTTTAGCCAATCCCATAAATCTGTTCTCAGTTCGGATCGCAG 1260 1261 TCTGCAACTCGACTGCGTGAAGCTGGAATCGCTAGTAATCGCGGATCAGCATGCCGCGGTGAATACGTTC 1330 1331 CCGGGCCTTGTACACACCGCCCGTCACACCACGAGAGTTTTCAACATCCGAAGTCGGTGAGGTAACCTTT 1400 1401 ATGGTAGCC

Figure 1. Partial nucleotide sequence of 16S rRNA gene of efficient isolates: (A) B. subtilis (MK5), (B) B. pumulis (MK7). 
Table 5. Pair wise genetic distance of the two efficient isolates with other selected sequences from the NCBI.

\begin{tabular}{|c|c|c|c|c|c|c|c|c|c|c|c|c|c|c|c|c|c|}
\hline Isolate & 1 & 2 & 3 & 4 & 5 & 6 & 7 & 8 & 9 & 10 & 11 & 12 & 13 & 14 & 15 & 16 & 17 \\
\hline \multicolumn{18}{|l|}{ B.subtilis (native isolate) } \\
\hline Bacillus subtilis strain MZA75 (HM101166) & 0.004 & & & & & & & & & & & & & & & & \\
\hline Bacillus subtilis strain RKJ700 (HM027881) & 0.004 & 0.000 & & & & & & & & & & & & & & & \\
\hline Bacillus subtilis strain PEBS2501 (HM01550) & 0.004 & 0.001 & 0.001 & & & & & & & & & & & & & & \\
\hline Bacillus sp. RFO41 (EF213022) & 0.004 & 0.000 & 0.000 & 0.001 & & & & & & & & & & & & & \\
\hline Bacillus subtilis strainSU-10 (GU902972) & 0.004 & 0.000 & 0.000 & 0.001 & 0.000 & & & & & & & & & & & & \\
\hline Bacillus subtilis strain 1369 (GU726871) & 0.004 & 0.000 & 0.000 & 0.001 & 0.000 & 0.000 & & & & & & & & & & & \\
\hline Bacillus subtilis strainSYST2 (GU568180) & 0.004 & 0.000 & 0.000 & 0.001 & 0.000 & 0.000 & 0.000 & & & & & & & & & & \\
\hline Bacillus sp. M307 (AB425345) & 0.004 & 0.000 & 0.000 & 0.001 & 0.000 & 0.000 & 0.000 & 0.000 & & & & & & & & & \\
\hline B.pumulis (native_isolate) & 0.037 & 0.038 & 0.038 & 0.038 & 0.038 & 0.038 & 0.038 & 0.038 & 0.038 & & & & & & & & \\
\hline Bacillus pumilusstrain B313 (GU904681) & 0.037 & 0.033 & 0.033 & 0.034 & 0.033 & 0.033 & 0.033 & 0.033 & 0.033 & 0.004 & & & & & & & \\
\hline Bacillus pumilus strain 1367 (GU726869) & 0.037 & 0.033 & 0.033 & 0.034 & 0.033 & 0.033 & 0.033 & 0.033 & 0.033 & 0.004 & 0.000 & & & & & & \\
\hline Bacillus pumilus strain BHK28 (AB360809) & 0.037 & 0.033 & 0.033 & 0.034 & 0.033 & 0.033 & 0.033 & 0.033 & 0.033 & 0.004 & 0.000 & 0.000 & & & & & \\
\hline Bacillus pumilus strain BD3-6 (GU332609) & 0.037 & 0.033 & 0.033 & 0.034 & 0.033 & 0.033 & 0.033 & 0.033 & 0.033 & 0.004 & 0.000 & 0.000 & 0.000 & & & & \\
\hline Bacillus sp. BT3-6 (GU332604) & 0.037 & 0.033 & 0.033 & 0.034 & 0.033 & 0.033 & 0.033 & 0.033 & 0.033 & 0.004 & 0.000 & 0.000 & 0.000 & 0.000 & & & \\
\hline Bacillus safensis strainAZ3-1 (GU332603) & 0.037 & 0.033 & 0.033 & 0.034 & 0.033 & 0.033 & 0.033 & 0.033 & 0.033 & 0.004 & 0.000 & 0.000 & 0.000 & 0.000 & 0.000 & & \\
\hline Bacillus pumilus strain Van35 (GU290547) & 0.037 & 0.033 & 0.033 & 0.034 & 0.033 & 0.033 & 0.033 & 0.033 & 0.033 & 0.004 & 0.000 & 0.000 & 0.000 & 0.000 & 0.000 & 0.000 & \\
\hline Pseudomonas aeruginosa (FJ985806) & 0.302 & 0.298 & 0.298 & 0.299 & 0.298 & 0.298 & 0.298 & 0.298 & 0.298 & 0.296 & 0.287 & 0.287 & 0.287 & 0.287 & 0.287 & 0.287 & 0.287 \\
\hline
\end{tabular}




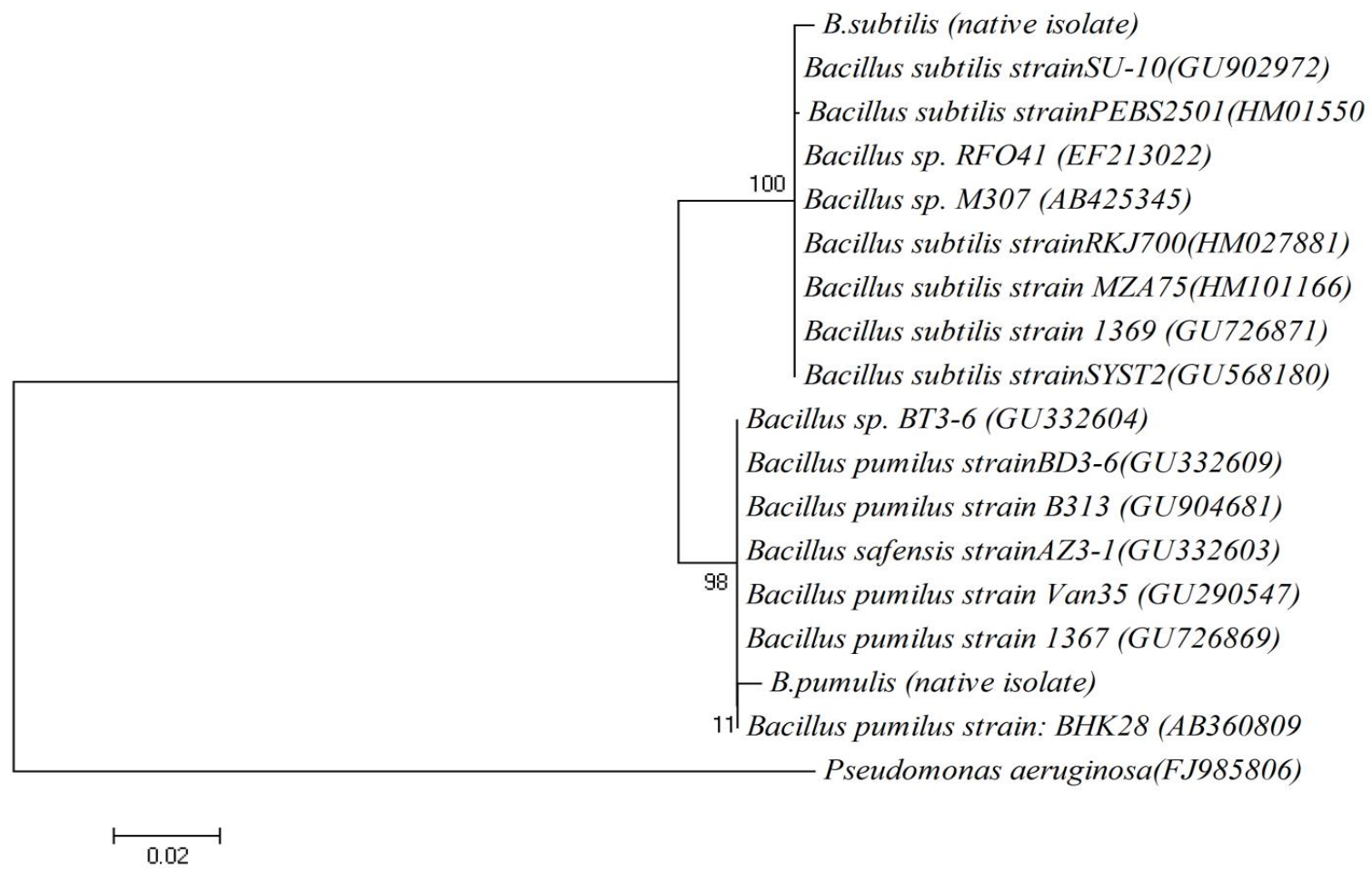

Plate 1. Phylogenetic tree constructed by Neighbor-Joining method derived from analysis of the 16S rRNA gene sequences of native isolates and related sequences obtained from NCBI. Scale bar, 0.02 substitutions per nucleotide position. 47

\section{REFERENCES}

Bakker AW, Schippers B (1987). Microbial cyanide production in the rhizosphere to potato yield reduction and Pseudomonas spp. mediated plant growth stimulation. Soil Biol. Biochem. 19:451-457.

Bray RH, Kurtz LT (1945). Determination of total organic and available forms of phosphorus in soils. Soil Sci. 59:39-45.

Catara V, Sutra L, Morineau A, Achouak W, Christen R, Gardan L (2002). Phenotypic and genomic evidence for the revision of Pseudomonas corrugata and proposal of Pseudomonas mediterranea sp. nov. Int. J. Syst. Evol. Microbiol. 52:1749-1758.

Chan YK, Barraquio WL, Knowles R (1994). $\mathrm{N}_{2}$-fixing pseudomonads and related soil bacteria. FEMS Microbiol. Rev. 13:95-118.

Clarridge JE (2004). Impact of 16S rRNA gene sequence analysis for identification of bacteria on clinical microbiology and infectious diseases. Clin. Microbiol. Rev. 17:840-862.

Cleyet-Marcel JC, Larcher M, Bertrand H, Rapior S, Pinochet X (2001). Plant growth enhancement by rhizobacteria In: Morot-Gaudry J-F, ed. Nitrogen assimilation by plants. Physiological, biochemical and molecular aspects. En field (NH, USA), Plymouth (UK): Science Publishers, pp. 184-197.

Dey R, Pal KK, Bhatt DM, Chauhan SM (2004). Growth promotion and yield enhancement of peanut (Arachis hypogaea L.) by application of plant growth-promoting rhizobacteria. Microbiol. Res. 159:371-394.

Gordon SA, Paleg LG (1957). Quantitative measurement of IAA. Plant Physiol. 10:37-38.

Jensen ES (1987). Inoculation of pea by application of Rhizobium in planting furrow. Plant Soil 97:63-70.

Kloepper JW, Schroth MN (1978). Plant growth-promoting rhizobacteria on radishes. In: Proceedings of the $4^{\text {th }}$ International Conference on Plant Pathogenic Bacteriology Vol. 2, Station de Pathologie Vegetale et Phytobacteriologie, INRA, Angers, France. pp. 879-882.
Lifshitz R, Kloepper JW, Kozlowski M, Simonson C, Carlson J, Tipping EM, Zalesca I (1987). Growth promotion of canola (rapeseed) seedlings by a strain of Pseudomonas putida under gnotobiotic conditions. Can. J. Microbiol. 33:390-395.

Minorsky PV (2008). On the inside. Plant. Physiol. 146:323-324.

Mirza MS, Ahmad W, Latif F, Haurat J, Bally R, Normand P, Malik KA (2001). Isolation, partial characterization, and the effect of plant growth-promoting bacteria (PGPB) on micro-propagated sugarcane in vitro. Plant Soil 237:47-54.

Pikovskaya RI (1948). Mobilization of phosphorus in soil in connection with the vital activity of some microbial species. Mikrobiologiya 17:362-370.

Relman DA (1999). The search for unrecognized pathogens. Science 284:1308-1310.

Schwyn B, Neilands JB (1987). Universal chemical analysis for the detection and determination of siderophores. Anal. Biochem. 160:4756.

Skrary FA, Cameron DC (1998). Purification and characterization of a Bacillus licheniformis phosphatase specific for d-alphaglycerphosphate. Arch. Biochem. Biophys. 349:27-35.

Verma SC, Ladha JK, Tripathy AK (2001). Evaluation of plant growth promoting and colonization ability of endophytic diazotrophs from deep water rice. J. Biotechnol. 91:127-141.

Vincent JM (1970). A manual for the practical study of root-nodule bacteria. Blackwell Scientific Publisher, Oxford, UK. 